\title{
Influência da audição musical na prática de exercícios físicos por pessoas adultas
}

CDD. 20.ed. 613.7

782

\author{
Nathália Sixel RODRIGUES* \\ Carlos Alberto de Andrade COELHO FILHO*
}

*Faculdade de Educação Físicae Desportos, Universidade Federal de Juiz de Fora

\section{Resumo}

Considerando a importância do conhecimento sobre os fatores que podem influenciar a aderência aos programas de exercícios fisicos, esta pesquisa, de natureza qualitativa, tem como objetivo verificar a influência da música na motivação para a prática da ginástica de participantes do projeto de extensão "Ginástica e equilíbrio estético". Para a coleta de dados empíricos foi utilizada a dinâmica dos "grupos focais". Foi constituído um "grupo focal", do qual participaram 14 mulheres. Tendo em vista a análise e a interpretação dos dados coletados, destacam-se as seguintes conclusões: 1) a música, no contexto da prática de exercícios físicos, pode conduzir o praticante ao estado de "fluxo ou fluência", também conhecido como "flow", favorecendo certo "esquecimento do cotidiano", gerando maior envolvimento com a atividade; 2) a música pode situar a prática do exercício físico na dimensão do jogo, pois quando o indivíduo mexe com o corpo, no rumo das vibrações musicais, ele "brinca com o corpo"; 3) a utilização dos pulsos musicais durante a prática de exercícios fisicos pode auxiliar na precisão e na velocidade de execução dos gestos motores, contribuindo com a motivação e com o rendimento grupal e individual; 4) no que se refere a certo estado subjetivo favorecido pela música, faz-se notar que as canções têm a capacidade de recuperar memórias, boas ou ruins, para uns e/ou para outros, e que, portanto, no interior de um grupo, esse efeito vai escapar a um possível controle objetivo; 5) o alto volume da música foi apontado como elemento desmotivador por gerar cansaço e irritabilidade.

Unitermos: Exercícios físicos; Adesão; Música.

\section{Introdução}

Com o avanço tecnológico, ocorreu uma transformação na relação do homem com o ambiente, diminuindo a necessidade de esforço físico cotidiano, tanto no trabalho como no lazer (GOBBI, VILAR \& ZAGO, 2005; RoJAs, 2003). Em virtude deste novo padrão de comportamento, a qualidade de vida da população ficou comprometida (TAHARA, SCHWARTZ $\&$ SiLva, 2003), por exemplo, no sentido da relação de causa e efeito que se pode estabelecer entre o sedentarismo e os agravos cardiovasculares, o câncer, a diabetes e a saúde mental (Lessa \& PitAnga, 2005).

Deste cenário emerge, de certa forma, uma situação paradoxal. De um lado, a população acredita nos benefícios da realização de exercícios físicos ${ }^{1}$ para a saúde (CASTRO, 2006), de outro, manter indivíduos ativos fisicamente de maneira regular tem se tornado um dos grandes desafios da saúde pública (ORGANIZaCión Mundial de La Salud, 2012). Muitas pessoas iniciam a prática de exercícios físicos estimuladas por várias razões, mas não conseguem incorporá-la ao seu cotidiano, deixando-a de lado na maioria das vezes (SANTOS \& KNIJNIK, 2006). Nesse sentido, considera-se a importância do conhecimento sobre os fatores que podem influenciar de forma positiva ou negativa a aderência ${ }^{2}$ aos programas de exercícios físicos (Costa, Bottcher \& KoKUbun, 2009).

Sobre esta aderência, Miranda e Souza (2009) afirmam que a música constitui-se em elemento valioso no contexto da prática de exercícios físicos. Para estas autoras, a natureza das atividades com música assemelha-se à das atividades prazerosas e facilita a autopercepção de competência e autodeterminação. Estima-se que o ambiente com música agradável possa criar um contexto que favoreça uma percepção positiva do exercício e do esforço para realizá-lo (MirANDA \& SouZA, 2009), atuando também como fator desinibidor 
do desconforto psicológico que a prática em locais públicos possa causar em alguns (SABA, 2003).

Para ArtaXo e Monteiro (2000), a música tonifica, exalta e alivia, induzindo a um esquecimento do corpo e suas fraquezas. Além disso, a música pode ser utilizada como uma forma de prevenção contra a monotonia existente na prática do exercício físico sistematizado (Miranda \& Godeli, 2002).

No mesmo diapasão, NaKamura, Deutsch e KoKubun (2008) dizem que o estilo de música preferido pode ocasionar alterações positivas no desempenho do exercício físico, distraindo os indivíduos das dores e desconfortos causados pelo mesmo; com o contraponto de que a música que não corresponde ao gosto das pessoas pode ser experienciada como um estímulo não prazeroso, causando piora nos estados de ânimo e no desempenho.

Sobre a relação entre exercício físico e música, portanto, importa observar que os estudos por nós revisados seguem, em geral, um referencial teórico-metodológico de coleta de dados com a aplicação de questionários fechados e/ou escalas de avaliação objetivas. Nesse sentido, como aponta MiRANDA (2001), a obtenção de relatos verbais, juntamente com as avaliações experimentais e/ou quantitativas, é de grande valia para a ampliação de informações relevantes.

Assim, analisar e interpretar qualitativamente a função e a influência da música no contexto da prática de exercícios físicos reveste-se de importância na medida em que tal análise e interpretação podem contribuir para aprofundar pontos que são assinalados nos estudos quantitativo-experimentais, favorecendo as tomadas de decisão com relação à escolha e utilização da música neste contexto, a fim de promover satisfação e bem-estar.

Considerando a representatividade do exercício físico na sociedade atual, este estudo tem como objetivo verificar a influência da música na motivação para a prática da ginástica de participantes do projeto de extensão "Ginástica e equilíbrio estético".

\section{Método}

Esta pesquisa, de natureza qualitativa, baseia-se na compreensão de que as pessoas agem em função de suas crenças, percepçóes, sentimentos e valores, e que seus comportamentos têm sempre um sentido, um significado que não se dá a conhecer de modo imediato, precisando ser desvelado (Alves, 1991).

Para coleta de dados, foi utilizada a dinâmica dos "grupos focais", que, segundo Morgan (1997), caracteriza-se como uma técnica de pesquisa que objetiva coletar dados por meio de interações grupais, discutindo-se tópicos especiais sugeridos pelo pesquisador.

O critério de inclusão de voluntários foi o de assiduidade no projeto de extensão "Ginástica e equilíbrio estético”. Este projeto, que está formalmente vinculado à Faculdade de Educação Física e Desportos da Universidade Federal de Juiz de Fora, oferece aulas de ginástica, com frequência semanal de três dias, em dois horários (duas turmas). Cada turma é composta em média por dezoito pessoas adultas, de ambos os sexos (merece destacar, contudo, que, na época da coleta de dados havia somente mulheres frequentando as aulas). É um projeto gratuito que, funcionando continuamente há mais de quatro anos, além de proporcionar aos membros da comunidade local um tempo/espaço para a prática regular da ginástica, agrega o objetivo de que os participantes tornem-se agentes de divulgação dos benefícios deste tipo de prática.

Como estratégia metodológica, optamos por comunicar (duas semanas antes do dia previsto para coleta de dados) às participantes do projeto (mulheres que estavam frequentando as aulas, e consequentemente possíveis voluntárias) sobre a realização da pesquisa e os propósitos da mesma. Assim, todas foram incentivadas a pensar "a priori" sobre a utilização da música no contexto da prática da ginástica em nosso projeto. Ainda com o intuito de propiciar uma maior reflexão sobre o tema, estabelecemos que nos dias subsequentes àquela comunicação/explanação e anteriores ao da coleta de dados, seriam ministradas duas aulas de ginástica em que utilizaríamos músicas e uma que não utilizaríamos música alguma (as aulas do projeto têm duração de uma hora). Em termos sumários, o planejamento dessas três aulas foi estruturado da seguinte maneira:

Aula 1 (músicas nacionais e internacionais de variados estilos, músicas "new age"): exercícios aeróbios coreografados realizados somente no solo (isto é, sem a utilização de "steps" ou "jumps", por exemplo), seguindo pulsos musicais de aproximadamente 145 batimentos por minuto (BPM); num segundo momento, exercícios de flexibilidade (alongamentos estáticos) realizados em colchonetes individuais, 
com fundo musical; por fim, descontração total (relaxação) também realizada com fundo musical nos colchonetes individuais.

Aula 2 (músicas nacionais e internacionais de variados estilos): exercícios de força seguindo pulsos musicais de aproximadamente 120 BPM, finalizando o trabalho (a aula) com exercícios de flexibilidade (alongamentos estáticos de baixa intensidade e pouco tempo de permanência nas posturas) realizados na barra fixa.

Aula 3 (realizada sem música): exercícios variados, estáticos e balísticos, e de conscientização corporal.

A coleta de dados ocorreu no dia 9 de fevereiro de 2011. Foi realizado apenas um "grupo focal", do qual participaram 14 mulheres. Todas as voluntárias foram esclarecidas sobre os propósitos do estudo e se prontificaram livremente a dele participar (assinando o Termo de Consentimento Livre e Esclarecido). O projeto foi aprovado pelo Comitê de Ética em Pesquisa com Seres Humanos da Universidade Federal de Juiz de Fora (parecer n 337/2010).

As questões mais gerais que nortearam as reflexões no "grupo focal" foram:

\section{Resultados e discussão}

\section{Música como fator motivacional}

Para Sena e Grecco (2011), o exercício físico acompanhado de música interfere nos estados de ânimo de seus praticantes de forma positiva, diminuindo a tristeza e o medo, tornando-os mais ativos. Na mesma direção, Moura, Grillo, Merida, CAMPANELli e MERida (2007) afirmam que a música ajuda no sentido de proporcionar benefícios psicológicos, aumentando a motivação e agindo como um elemento de distração do desconforto, além de tornar a atividade mais agradável. Sobre o assunto, portanto, observemos o seguinte depoimento: "Nunca consegui fazer educação física, ginástica, é..., por tanto tempo igual estou conseguindo desta vez; nunca tive esta disciplina. É a primeira vez que eu estou tendo sequência. Então, é a música né? A música é mágica. É magia” (P3).

Segundo Artaxo e Monteiro (2000), tal disciplina se evidencia em virtude das vibrações musicais provocarem vibrações corporais, fazendo com que o praticante se sinta purificado pela beleza do gesto em particular, participando ao máximo da aula. Isso pode ocorrer também pelo somatório de influências dos diferentes componentes musicais, já que cada
1) Qual a função da música no contexto da prática da ginástica em nosso projeto?

2) Quais as sensações passadas a vocês pelos diferentes estilos de música utilizados durante as aulas de ginástica no nosso projeto?

Como referencial teórico para a análise dos dados coletados, utilizamos a "análise de conteúdo", quando então privilegiamos a proposta de análise temática/categorial de BARDIN (1977). Para esta autora, a "análise de conteúdo" se caracteriza como um instrumento para análise de dados oriundos de mensagens transcritas, em nosso caso, provenientes da dinâmica do grupo focal, e busca reagrupar ideias em categorias segundo o desmembramento do texto em unidades analógicas. Nesse sentido, e diretamente associada ao nosso objeto de estudo, elegemos como categoria de análise: "Música como fator motivacional".

As 14 participantes do grupo focal são identificadas pela letra $\mathrm{P}$, seguida dos números 1 a 14 . Ou seja, a participante 1 é identificada como P1, e assim sucessivamente.

um deles, segundo Miranda (2001), tem sua atuação: o ritmo na forma de realização dos movimentos, tornando-os mais ou menos vigorosos ou fluentes; a melodia nos sentimentos e emoções; a harmonia nos pensamentos e associações. Tal influência musical sobre componentes corporais psicofisiológicos, de acordo com Smirmaul, Dantas, Fontes e Morais (2011), confirma a Teoria da Atenção Restrita, segundo a qual o cérebro possui uma quantidade limitada de informaçôes que pode ser processada ao mesmo tempo. Assim, a música acabaria por inibir sensações desagradáveis resultantes do exercício físico, por exemplo, associadas à fadiga, diminuindo a atenção do indivíduo a essas sensações, aumentando a motivação para a tarefa e protelando o ponto de exaustão (Tenenbaum, Lidor, Lavyan, Morrow, Tonnel \& Gershgoren, 2004). Ou seja, a música atua como um "propulsor" para a movimentação corporal: "Acho que a música é um estímulo. E na atividade física, é bom ter alguma coisa para te ajudar a fazer né? Normalmente..., o normal é a gente ficar parado" (P10).

A música também foi apontada como fator positivo por reforçar a sensação de "desligamento", indicando, em certo sentido, o estado de "fluxo ou fluência", 
também denominado de "flow". Para CsIKSZENTMIHALYI (1999), o "flow" pode ser caracterizado como o estado no qual o indivíduo encontra-se intrinsecamente motivado e totalmente envolvido e absorvido na atividade que realiza, sem preocupar-se com o efeito de suas açōes. Durante a experiência do "flow", há uma contração do campo perceptivo, um aumento da autoconsciência e do sentido de fusão com a atividade e com o ambiente, sendo um estado muito positivo e prazeroso (CsiKSZENTMIHALYI, 1999). Observemos os dois trechos a seguir.

No ano passado eu tive uns momentos meio difíceis de doença na família, aí quando eu vinha para a ginástica eu não sei se era calma, mas eu conseguia me desligar. Aí eu acho que eu ficava calma. Porque era um momento que eu me desligava dos problemas e esquecia um pouco, até porque tem que prestar atenção, tem que lembrar a sequência. Eu acho que é uma espécie de calma também. Acompanhando a música você esquece (P9).

Junto com o exercício, uma característica dessa aula para mim é me esquecer do resto. É ficar voltada para mim, me concentrar naqueles movimentos que eu estou fazendo, escutar a música e esquecer completamente. Igual, eu saio do trabalho e venho imediatamente de lá para cá, eu me desligo completamente. Então, tem esse componente da música e exercício na concentração. É uma espécie de meditação que a gente faz (P7).

No mesmo sentido de desligamento, Coelho FilHo (2007) diz que, através de inúmeras associações, a prática do exercício físico pode representar "esquecimento do cotidiano", como na meditação, em que buscamos o desapego dos pensamentos que conduzem ao sofrimento.

Ainda sobre as sensações despertadas pela música, o remeter a lembranças associadas a ela, emerge como possibilidade: "De repente a música pode te remeter a uma situação..., porque a música tem isso..., a gente liga muito a música a uma coisa que aconteceu" (P9).

Como destaca Miranda (2001), a música age interferindo no fator motivacional de quem ouve, gerando respostas afetivas, provocando sentimentos e sensações; a música tem a capacidade de induzir o ouvinte a fazer associaçóes extramusicais e/ou intrassubjetivas, evocando histórias e imaginando cenas. Assim elucida o depoimento: "Eu penso em paisagem, eu não penso em dor de cotovelo não. Dor de cotovelo é ruim. Só numa paisagem relaxante" (P3).
É essencial ressaltar, nesse ponto, que a música pode também provocar lembranças ruins, ocasionando o aparecimento de afetos negativos (MIRANDA \& Godeli, 2002), consequentemente, piorando os estados de ânimo e diminuindo o desempenho (SenA \& GrecCo, 2011). Como assinala, indiretamente, a participante: "eu não penso em dor de cotovelo não". Mas como podemos evitar esta dimensão negativa da audição musical nas atividades realizadas em grupo, já que uma mesma música pode gerar associações boas e ruins, para uns e para outros, respectivamente? Esta é uma questão para a qual não encontramos resposta.

Outro ponto citado pelas participantes nos remete para a relação que se pode estabelecer entre a música, a prática da ginástica e o jogo. Como diz BUYTENDIJK (1977), os jogos muitas vezes significam exercícios físicos, que podem se constituir como meios adequados para o sujeito se sentir fisicamente disposto e forte, confirmado pela participante quando comenta: "A própria música já faz você mexer, para cima, e quando vê, a gente já está no ritmo" (P8).

Mais ainda. Quando mexemos o corpo, produzimos, a partir de um impulso de tensão, uma aparência que, pelo olhar e pela própria percepção, volta para nós, estimulando nova tensão (GADAMER, 1999). Ou seja, mexer com o corpo é brincar com o corpo, que brinca conosco. Assim, o jogo torna-se dono do jogador, ele o mantém escravizado (GADAMER, 1999). Observemos o que diz a participante: "[...] ela chega aqui..., cada um no seu lugar..., espalha. Aí liga o som e já começa mexer" (P8).

A utilização dos pulsos musicais durante as práticas foi também sinalizada como elemento motivador:

Porque parece muito com a dança. Eu acho que é por isso que incentiva. Porque a dança é isso, é seguir o pulso musical. Quando você faz a ginástica seguindo o pulso musical é como se fosse uma dança, e a dança é uma coisa boa (P10).

Teve uma aula, aquela aula de luta, com aqueles movimentos de lutas. Eu não me lembro a música também, mas teve um dia que eu fiquei encantada. Eu olhava assim e todo mundo fazendo igual. Eu não me lembro que música que foi, mas eu achei assim, que combinou demais a música com a aula. Acho que isso também deixa a gente empolgada a fazer (P9).

Moura et al. (2007) identificaram que componentes da música como pulsação e ritmo influenciam na prática de exercícios físicos, ambos auxiliando 
na precisão e velocidade dos gestos motores. Nesse sentido, a intensidade do exercício pode ser controlada por meio do pulso musical, já que o mesmo impõe uma velocidade de execução do movimento de forma similar ao metrônomo (SENA \& GRECCO, 2011). Sobre o mesmo tema, e sublinhemos a relação que se estabeleceu no extrato acima entre ginástica e dança ("[...] a ginástica seguindo o pulso musical é como se fosse uma dança [...]”), ARTAXO e MonTEIRO (2000) apresentam o pulso musical como a constância regular das batidas que estabelecem a base da música, que, juntamente com o ritmo, sendo este caracterizado como acentuações e alternâncias dos tempos fortes e fracos, estimula a reação corporal, conhecida como dança. Para estas autoras, a música auxilia na incorporação da técnica, na qualidade e dosagem dos movimentos, contribuindo para retardar a fadiga e maximizar o resultado.

No entanto, a partir dos depoimentos das participantes, observamos: se de um lado a correlação entre os movimentos e os pulsos musicais pode ser um incentivo, de outro, se tal estratégia não é convenientemente utilizada, pode provocar insatisfação e consequente desmotivação.

Se o exercício exige um ritmo, uma cadência e a música que está tocando tem aquela cadência, mas o professor ou as próprias pessoas não a seguem, aquele ritmo, isso pra mim é ruim. Às vezes a música está adaptada, mas o professor não está nem aí para a conexão entre o pulso e a execução. Isso para mim é ruim. Me atrapalha e eu perco o interesse pela aula. Para mim a música nessa questão do pulso é..., quando o exercício exige, para mim é essencial (P7).

Segundo Monteiro, Silva, Monteiro e Arruda (1999), tal incômodo e desinteresse se evidenciam pelo fato de que a não utilização dos pulsos musicais pode interferir diretamente na velocidade de execução dos movimentos, consequenciando em uma alteração na intensidade da aula. No entanto, mesmo quando tal elemento musical é utilizado, pessoas podem ainda apresentar dificuldades em coordenar as marcações musicais com a realização dos gestos motores, o que influencia substancialmente no rendimento, tanto individual quanto da turma. Sobre tal dificuldade, ArTaXo e Monteiro (2000) afirmam que a ritmicidade pode ser treinada e aperfeiçoada pelos indivíduos arrítmicos, utilizando-se das marcaçôes musicais para realização de movimentos. Evidencia-se assim a importância do professor como incentivador de práticas que estimulem a conjugação dos pulsos musicais com as tarefas motoras, uma vez que os alunos percebem ou apontam sua não utilização: "A maioria dos professores coloca a música como fundo e não como..., é..., um indicativo, como ritmo" (P7).

Ainda sobre elementos musicais que podem levar à desmotivação e não aderência aos exercícios físicos, o volume excessivo do som é apontado:

Eu me lembrei agora de uma época que eu fazia esteira em uma academia, após trabalhar oito horas. No mesmo espaço tinha uma aula de 'spinning' e era uma música muito alta. O professor gritava o tempo todo e eu ficava na esteira olhando para a televisão. Só via as imagens. Aí eu parava até de olhar, porque às vezes eu queria saber o que estava acontecendo e não tinha jeito. Aquilo começou a me irritar, eu começava sentir que eu estava cansada, ficava doida para parar com aquilo. Aí eu parei. Era o horário que eu podia ir e não conseguia porque era uma música que me irritava. Desconforto, irritabilidade. Eu começava a me sentir cansada, ficava doida para acabar aquilo e parei de fazer (P9).

A música estando alta, o professor tem que falar muito alto. Então fica aquela barulheira..., não é motivador (P6).

Almeida, Albernaz, Zaia, Xavier e Karazawa (2000) afirmam que a exposição ao ruído, caracterizado de forma simples como um som incômodo, pode gerar como consequência principal a perda auditiva; pode ocasionar também outros agravos de menor impacto, mas não menos importantes à saúde, como hipertensão arterial, acidentes de trabalho, estresse agudo e lesões no ouvido. PALma, Mattos, Almeida e Oliveira (2009), por seu turno, ressaltam que o efeito da pressão sonora no indivíduo não depende apenas de suas características (amplitude, frequência, duração), mas também da própria percepção individual.

É cansativo. Você acaba saindo daquilo mais..., mais cansado, mais estressado. Porque tem academia que a gente passa perto, dá medo. Eu não iria lá nunca, porque a gente já está agitado, o dia a dia exige muito. Se eu for a uma academia que a música é muito alta eu não aguento (P3).

Mediante o quadro prejudicial apresentado pelo volume excessivo do som, torna-se necessário um aumento de esforços para eliminação e/ou controle deste agente (AlmeidA et al., 2000; SENA \& GRECCO, 2011).

A seleção musical de acordo com as preferências (nacional ou internacional, vocal ou somente instrumental) é apontada como elemento motivador. Os 
depoimentos, não consensuais, nos remetem para certas preferências que são associadas a momentos distintos das aulas: "Para mim, quando é ritmo, tanto faz, sendo brasileira ou internacional, para mim é a mesma coisa” (P3).

Tal situação emerge, de acordo com Moura et al. (2007), pelo fato dos pulsos musicais passarem informações sobre precisão, velocidade e tempo de realização dos movimentos, sendo destacadas como de menor significado outras informações que poderiam ser transmitidas pela música.

Já nos momentos em que as músicas são utilizadas para relaxamento, observemos, na sequência, a pluralidade de opiniōes: "Eu gosto do relaxamento com uma música mais orquestrada, só fundo. Porque aí você relaxa mesmo. Você não presta atenção em nada, você não se preocupa com a letra, então você relaxa, viaja mesmo. Eu gosto mais" (P4). De acordo com Valim, Elaine, Volp e Deutsch (2002), o motivo de predileção por este tipo de música com andamento lento, ritmo regular sem mudanças bruscas e melodia fluente, deve-se ao fato de tal organização proporcionar diminuição tanto da frequência cardíaca quanto de hormônios estressores do organismo. Tal diminuição aproximaria o ritmo cardíaco ao de repouso, o que facilitaria o estado de relaxamento. Em certo sentido, é o que apontam SMirmaul et al. (2011) quando afirmam que canções suaves, sem o predomínio de ritmo e com supremacia da melodia, sendo muitas delas instrumentais, facilitam o relaxamento corporal.

Outra parte do grupo sinalizou predileção pelas músicas vocais, e "das nossas": "A música é essa harmonia..., eu penso assim..., que é a harmonia entre a letra e o som. É quando vocês estão finalizando a

\section{Considerações finais}

Tendo em vista a análise e a interpretação dos dados empíricos coletados no presente estudo, destacamos as seguintes conclusões: 1) a música, no contexto da prática de exercícios físicos, pode conduzir o praticante ao estado de "fluxo ou fluência”, também conhecido como "flow" (CSIKSZENTMIHALYI, 1999), favorecendo certo "esquecimento do cotidiano" (CoElHo Filho, 2007), gerando maior envolvimento com a atividade; 2) a música pode situar a prática do exercício físico na dimensão do jogo, pois quando o indivíduo mexe com o corpo, no rumo das vibrações musicais, ele "brinca com o ginástica, prestar atenção nessa música mais lenta no final. Para relaxar eu gosto mais das nossas" (P3). E, ainda: "Eu tento prestar mais atenção na letra, para me levar a outro estado. E principalmente quando é brasileira que eu prefiro" (P1).

Em estudo com mulheres praticantes de ginástica em academia, Moura et al. (2007) apontam que os ritmos nacionais têm grande aceitação, tanto pela multiplicidade de estilos ("rock", axé, "funk", anos 80, MPB), evitando-se assim a monotonia, quanto pelo significado das palavras e frases (letras de música) que podem melhorar os estados subjetivos das praticantes.

De forma geral, as preferências musicais são pessoais, podendo ou não ser modificadas (SMIRMAUL et al., 2011; VAlim et al., 2002). Como indica PorCHER (1982), a escolha da audição musical para a prática de exercícios físicos pode não estar associada apenas aos seus benefícios fisiológicos, mas estar vinculada significativamente ao nível de cultura musical do indivíduo. Nesse sentido, é importante registrar que a cultura, funcionando como um mecanismo de controle não necessariamente coercitivo, pelas diversas formas de comunicação simbólica, acaba conduzindo a vida dos indivíduos (STIGGER, 2009).

Portanto, no sentido do que afirmam KaraGEORghis, Mouzourides, Priest, Sasso, Morrish e WalLEY (2009), inúmeras iniciativas que visam a combater a prevalência de inatividade física na sociedade ocidental contemporânea têm sido consideradas pelos diferentes ramos da Educação Física. Assim, a música se apresenta como importante aliado na manutenção das práticas físicas, oferecendo informaçōes temporais para os gestos motores e favorecendo maior atitude mental e distração (VALIM et al., 2002). corpo" (GADAMER, 1999); 3) a utilização dos pulsos musicais durante a prática de exercícios físicos pode auxiliar na precisão e na velocidade de execução dos gestos motores (velocidade que se relaciona com intensidade), contribuindo com a motivação e com o rendimento grupal e individual; 4) nos exercícios em que os movimentos estão sendo direcionados pelos pulsos musicais, como, por exemplo, os aeróbios e os de força muscular, não emergem predileções no sentido de a música ser nacional ou internacional, vocal ou somente instrumental; 5) nos exercícios de relaxamento realizados com fundo musical, uma 
parcela de praticantes prefere as músicas orquestradas, isto é, somente instrumentais, alegando que esse tipo de música é mais favorável à relaxação objetivada pelo fato de não ter uma letra que possa, por algum motivo, direcionar a atenção, e outra parcela prefere as músicas vocais, mais precisamente as nacionais, uma vez que o significado da letra pode favorecer certo estado subjetivo, positivo; 6) no que se refere a este certo estado subjetivo favorecido pela música, destaca-se que as canções têm a capacidade de recuperar memórias, boas ou ruins, para uns e/ ou para outros, e que, portanto, no interior de um grupo, esse efeito vai escapar a um possível controle mais objetivo; 7) a altura da música (volume considerado demasiadamente alto) também foi apontada como elemento desmotivador por gerar cansaço e irritabilidade, além dos possíveis danos à saúde a ela associados.

Por fim, salientamos a importância das constataçôes do presente estudo, sobretudo quando consideramos as possibilidades de aplicação nas variadas manifestaçôes da ginástica contemporânea. Acreditamos que essas constatações podem se apresentar como informações instigadoras para os profissionais que hoje estão envolvidos com os diferentes espaços/momentos destinados à prática de exercícios físicos, visto que identificar elementos que influenciam de forma positiva a motivação para estas práticas pode ser de grande valia no sentido de manter indivíduos ativos fisicamente.

\title{
Notas
}

1. Destacamos certa distinção entre atividade física e exercício físico. Atividade física pode ser entendida de forma genérica, isto é, associada aos mais variados movimentos corporais, e que resulta em gasto de energia maior do que os níveis de repouso. Exercício físico, por sua vez, pode ser entendido como uma atividade física planejada, ou, em outras palavras, uma atividade física sistematizada que tem como objetivo a promoção e/ou a manutenção da saúde (CHEIK et al., 2003). A prática da ginástica, por exemplo, pode ser entendida, portanto, em certo sentido como exercício físico, mas também como atividade física.

2. Aderência caracteriza-se pela manutenção de uma atitude/comportamento/prática por um longo período de tempo, com poucas chances de desistência (BraWley, Martin \& GyurCsic, 1998; Culos-Reed et al., 2000).

\begin{abstract}
Influence of the music listening in the physical exercises of adult people

Considering the importance of the knowledge about the aspects influencing the adherence to physical exercises programs, this qualitative research, aims to verify the influence of the music as a motivation to the gymnastic practice in the project "Gymnastic and aesthetic balance". To collect empirical data we used the dynamics of focus groups. Fourteen women took part in one of these groups. Considering the analysis and interpretation of the collected data, we highlight the following conclusions: 1) the music in the context of the physical exercises practices can lead the practitioner into a state of "flow or creep" favoring certain oblivion of everyday life, generating greater involvement in the activity; 2 ) the music can put the practice of physical exercises in the dimension of the play, as when a person moves the body in the direction of the musical vibration, he/she "plays with the body"; 3) the use of musical pulses during the practice of physical exercises may help the accuracy and speed of motor gestures, contributing to the motivation and to the income of both, the group and the individual; 4) concerning a subjective state favored by music, it is possible to observe that the songs have the power to retrieve good or bad memories for some people and therefore, within a group, this effect will escape a possible objective control; 5) high music volume was appointed as a demotivating factor for generating tiredness and irritability.
\end{abstract}

Uniterms: Physical exercises; Accession; Music. 


\section{Referências}

ALMEIDA, S.I.C.; ALBERNAZ, P.L.M.; ZAIA, P.A.; XAVIER, O.G.; KARAZAWA, E.H.I. História natural da perda auditiva ocupacional provocada por ruído. Revista da Associação Médica Brasileira, São Paulo, v.46, n.2, p.143-58, 2000. ALVES, A.J. O planejamento de pesquisas qualitativas em educação. Cadernos de Pesquisa, São Paulo, v.77, p.53-61, 1991. ARTAXO, I.; MONTEIRO, G.A. Ritmo e movimento. Guarulhos: Phorte, 2000.

BARDIN, L. Análise de conteúdo. Lisboa: Ediçōes 70, 1977.

BRAWLEY, L.R.; MARTIN, K.A.; GYURCSIC, N.C. Problems in assessing perceived barriers to exercise: confusing obstacles with attributions and excuses. In: DUDA, J.L. Advances in sports and exercise psychology measurement. Morgantown: Fitness Informations, 1998. p.337-50.

BUYTENDIJK, F.J.J.U. O jogo humano. In: GADAMER, H.G.; VOGLER, P. Nova antropologia: o homem em sua existência biológica, social e cultura. São Paulo: EPU/EDUSP, 1977. p.63-87.

CASTRO, M.S. Motivos que influenciam a adesão à prática de exercícios físicos nos programas oferecidos pelo serviço social do comércio (SESC) no Distrito Federal. 2006. Dissertação (Mestrado em Educação Física) - Universidade Gama Filho, Rio de Janeiro, 2006.

CHEIK, N.C.; REIS, I.T.; HEREDIA, R.A.G.; VENTURA, M.L.; TUFIK, S.; ANTUNES, H.K.M.; MELLO, M.T. Efeitos do exercício físico e da atividade física na depressão e ansiedade em indivíduos idosos. Revista Brasileira de Ciência e Movimento, São Paulo, v.11, n.3, p.45-52, 2003.

COELHO FILHO, C.A.A. Metamorfose de um corpo andarilho: busca e reencontro do algo melhor. São Paulo: Casa do Psicólogo, 2007.

COSTA. B.V.; BOTTCHER L.B.; KOKUBUN, E. Aderência a um programa de atividade física e fatores associados. Revista Motriz, Rio Claro, v.15, n.1, p.25-36, 2009.

CSIKSZENTMIHALYI, M. A descoberta do fluxo: a psicologia do envolvimento com a vida cotidiana. Rio de Janeiro: Rocco, 1999.

CULOS-REED, S.N.; REJESKI, W.J.; McAULEY, E.; OCKENE, J.K.; ROTER, D.L. Predictors of adherence to behavior change interventions in the elderly. Controlled Clinical Trials, New York, v.21, p.200-5, 2000.

GADAMER, H.G. Verdade e método: traços fundamentais de uma hermenêutica filosófica. 3. ed. Petrópolis: Vozes, 1999. GOBBI, S.; VILLAR, R.; ZAGO, A.S. Bases teórico-práticas do condicionamento físico. Rio de Janeiro: Guanabara Koogan, 2005.

KARAGEORGHIS, C.I.; MOUZOURIDES, D.A.; PRIEST, D.L.; SASSO, T.A.; MORRISH, D.J.; WALLEY, C.L. Psychophysical and ergogenic effects of synchronous music during treadmill walking. Journal of Sport \& Exercise Psychology, London, v.31, p.18-36, 2009.

LESSA, I. PITANGA, F.J.G. Prevalência e fatores associados ao sedentarismo no lazer em adultos. Caderno Saúde Pública, Rio de Janeiro, v.21, n.3, p.870-7, 2005.

MIRANDA, M.L.J. Efeitos da atividade física com música sobre estados subjetivos de idosos. 2001. Tese (Doutorado em Psicologia) - Universidade de São Paulo, São Paulo, 2001.

MIRANDA, M.L.J; GODELI, M.R.C.S. Avaliação de idosos sobre o papel e a influência da música na atividade física. Revista Paulista de Educação Física, São Paulo, v.16, n.1, p.86-99, 2002.

MIRANDA, M.L.J; SOUZA, M.R. Efeitos da atividade física aeróbia com música sobre estados subjetivos de idosos. Revista Brasileira de Ciência do Esporte, Campinas, v.30, n.2, p.151-67, 2009.

MONTEIRO, A.G.; SILVA, S.G.; MONTEIRO, G.A.; ARRUDA, M. Efeito do andamento musical sobre a frequência cardíaca em praticantes de ginástica aeróbica com diferentes níveis de aptidão cardiorrespiratória. Revista Brasileira de Atividade Física e Saúde, São Paulo, v.4, n.2, p.30-8,1999.

MORGAN, D.L. Focus group as qualitative research. 2nd. ed. London: Sage, 1997.

MOURA, N.L.; GRILLO, D.E.; MERIDA, M.; CAMPANELLI, J.R.; MERIDA, F. A influência motivacional da música em mulheres praticantes de ginástica em academia. Revista Mackenzie de Educação Física e Esporte, São Paulo, v.6, n.3, p.103-18, 2007.

NAKAMURA, P.M.; DEUTSCH, S.; KOKUBUN, E. Influência da música preferida e não preferida no estado de ânimo e no desempenho de exercícios realizados na intensidade vigorosa. Revista Brasileira de Educação Física, São Paulo, v.22, n.4, p.247-55, 2008.

ORGANIZACIÓN MUNDIAL DE LA SALUD. Inactividad física: un problema de salud pública mundial. 2012. Disponível em: http://www.who.int/dietphysicalactivity/factsheet_inactivity/es/index.html. Acesso em: 02 fev. 2012.

94 • Rev. bras. Educ. Fís. Esporte, São Paulo, v.26, n.1, p.87-95, jan./mar. 2012 
PALMA, A.; MATTOS, U.A.O.; ALMEIDA, M.N.; OLIVEIRA, G.E.M.C. Nível de ruído no ambiente de trabalho de professores de educação física em aulas de ciclismo indoor. Revista Saúde Pública, São Paulo, v.43, n.2, p.345-51, 2009. PORCHER, L. Educação artística: luxo ou necessidade? 7. ed. São Paulo: Summus Editorial, 1982.

ROJAS, P.N.C. Aderência a programas de exercícios físicos em academias de ginástica na cidade de Curitiba - PR. 2003. Dissertação (Mestrado em Educação Física) - Universidade Federal de Santa Catarina, Florianópolis, 2003.

SABA, F. Mexa-se: atividade física, saúde e bem estar. São Paulo: Takano, 2003.

SANTOS, S.C.; KNIJNIK, J.D. Motivos de adesão à prática de atividade física na vida adulta intermediária. Revista Mackenzie de Educação Física e Esporte, Barueri, v.5, n.1, p.23-34, 2006.

SENA, K.S.; GRECCO, M.V. Comportamento da frequência cardíaca em corredores de esteira ergométrica na presença e na ausência de música. Revista Brasileira de Fisiologia do Exercício, São Paulo, v.10, n.3, p.156-61, 2011.

SMIRMAUL, B.P.C.; DANTAS, J.L.; FONTES, E.B.; MORAIS, A.C. Efeitos da música eletrônica nos sistemas neuromuscular, cardiovascular e parâmetros psicofisiológicos durante teste incremental exaustivo. Revista Motricidade, Montes Claros, v.7, n.3, p.11-8, 2011.

STIGGER, M.P. Lazer, cultura e educação: possíveis articulações. Revista Brasileira de Ciência do Esporte, Porto Alegre, v.20, n.2, p.73-88, 2009.

TAHARA, A.K.; SCHWARTZ, G.M.; SILVA, K. A. Aderência e manutenção da prática de exercícios em academias. Revista Brasileira de Ciência e Movimento, Brasília, v.11, n.4, p.7-12, 2003.

TENENBAUM, G.; LIDOR, R.; LAVYAN, N.; MORROW, K.; TONNEL, S.; GERSHGOREN, A. The effect of music type on running perseverance and coping with effort sensations. Psychology of Sport and Exercise, Amsterdam, v.5, n.2, p.89-109, 2004.

VALIM, P.C.; ELAINE, C.B.; VOLP, C.M.; DEUTSCH, S. Redução de estresse pelo alongamento: a preferência musical pode influenciar? Revista Motriz, Rio Claro, v.8, n.2, p.51-6, 2002.

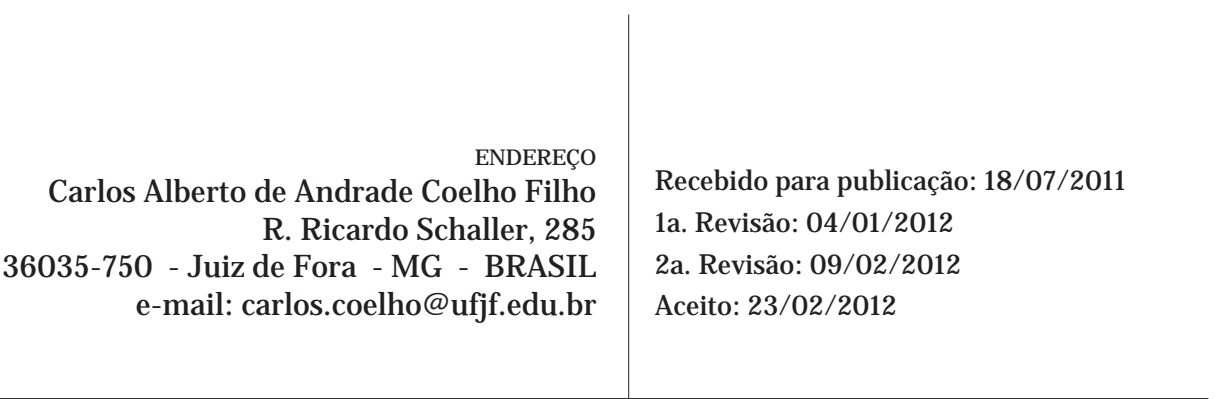

